
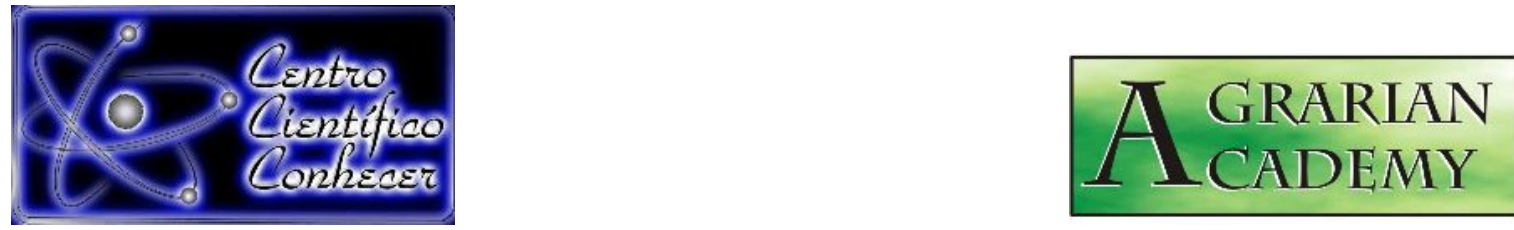

\title{
USO DE DIFERENTES TÉCNICAS PARA DESCRIÇÃO DA ALTURA DE UM PLANTIO MONOESPECÍFICO DE ANGICO-VERMELHO
}

Matheus Teixeira Martins ${ }^{1}$; Gabriel Paes Marangon²; Emanuel Arnoni Costa ${ }^{3}$; Maiquel Ivo Pfeifer ${ }^{4}$; Bruna Denardin da Silveira ${ }^{5}$

${ }^{1}$ Graduando em Engenharia Florestal, Universidade Federal do Pampa, São

Gabriel, RS, Brasil (mteixeiramartins@gmail.com).

2 Prof. Dr. do Curso de Engenharia Florestal, Universidade Federal do Pampa, São Gabriel, RS, Brasil.

${ }^{3}$ Prof. Dr. do Curso de Engenharia Florestal, Universidade Federal de Uberlândia, Monte Carmelo, MG, Brasil.

${ }^{4}$ Graduando em Engenharia Florestal, Universidade Federal do Pampa, São Gabriel, RS, Brasil.

${ }^{5}$ Prof. Dr. do Curso de Engenharia Florestal, Universidade Federal do Pampa, São Gabriel, RS, Brasil.

Recebido em: 02/06/2019 - Aprovado em: 15/06/2019 - Publicado em: 22/07/2019 DOI: 10.18677/Agrarian_Academy_2019a32

RESUMO

O uso de modelagem estatística para estimar altura de árvores é uma forma de reduzir o custo e tempo do levantamento de dados no inventário florestal. Neste contexto, o presente estudo teve como objetivo comparar a análise de regressão com redes neurais artificiais (RNA) na predição de altura de um plantio monoespecífico de Parapiptadenia rigida (Benth.) Brenan conhecida popularmente como angico-vermelho, no munícipio de São Gabriel, no estado Rio Grande do Sul. Foram medidos altura e diâmetro à altura do peito (DAP) de 196 árvores individuais. Destes $70 \%$ foram separados para ajuste e $30 \%$ para validação. Foram ajustados e validados cinco modelos hipsométricos e destes selecionado o melhor de acordo com o resultado estatístico de validação e treinadas cem redes neurais artificiais do tipo Multylayer Perceptron para cada quantidade de neurônios na camada oculta (1,2,3 e 4 neurônios) e destas foram selecionadas três redes de acordo com a eficiência das estimativas (100\%, 90\% e $80 \%)$ para ser feita a validação. Através dos resultados estatísticos foi selecionada a melhor RNA. Os resultados indicaram que ambas as técnicas foram eficientes, porém a RNA apresentou melhores resultados estatísticos $\left(r_{\mathrm{YY}}=0,8319\right.$ e $\left.R Q M E= \pm 0,6812 \mathrm{~m}\right)$ em relação ao modelo hipsométrico ( $\mathrm{r}_{\mathrm{Y}}=0,8067$ e $\mathrm{RQME}= \pm 0,7362 \mathrm{~m}$ ).

PALAVRAS-CHAVE: inteligência artificial, inventário florestal, mensuração, Parapiptadenia rigida. 


\title{
USE OF DIFFERENT TECHNIQUES TO DESCRIBE THE HEIGHT OF A MONOSPECIFIC PLANTING OF ANGICO-RED
}

\begin{abstract}
The use of statistical modeling to estimate tree height is a way to reduce the cost and time of data collection in the forest inventory. In this context, the present study had the objective of comparing the regression analysis with artificial neural networks (ANN) on the prediction of height of a monospecific planting of Parapiptadenia rigida popularly known as angico-red in the municipality of São Gabriel, in the state of Rio Grande do Sul. Height and diameter at the chest height (DBH) of 196 individual trees were measured. Of these $70 \%$ were separated for adjustment and $30 \%$ for validation. Five hypsometric models were adjusted and validated, and the best selected according to the statistical validation result and trained one hundred artificial neural networks of the Multylayer Perceptron type for each number of neurons in the hidden layer (1,2,3 and 4 neurons) and of these three networks were selected according to the efficiency of the estimates $(100 \%, 90 \%$ and $80 \%)$ to be validated. Through the statistical results the best RNA was selected. The results indicated that both techniques were efficient, but RNA presented better statistical results $r_{\mathrm{Yr}}=0.8319$ and $\mathrm{RQME}= \pm 0.6812 \mathrm{~m}$ ) in relation to the hypsometric model $\mathrm{r}_{\mathrm{Y} \hat{\mathrm{Y}}}=0.8067$ and RQME $= \pm 0.7362 \mathrm{~m}$ ).
\end{abstract}

KEYWORDS: artificial intelligence, forest inventory, measurement, Parapiptadenia rigida.

\section{INTRODUÇÃO}

São encontrados na literatura florestal diversos modelos para estimar altura total de árvores que podem ser utilizados para diferentes espécies. Devido a mensuração dessa variável apresentar um custo significativo nos inventários florestais, torna-se importante realizar estudos voltados à modelagem, aos procedimentos e aos equipamentos de mensuração da altura (VENDRUSCOLO et al., 2017).

A relação entre as variáveis altura e diâmetro não é muito forte, devido a alta variabilidade das alturas para uma mesma classe de diâmetro. Portanto, a inclusão de variáveis qualitativas nos modelos hipsométricos é importante para que sejam obtidas estimativas mais próximas dos valores reais observados. Entretanto, adicionar variáveis qualitativas em modelos de regressão nem sempre geram ganho de exatidão, uma vez que a inclusão dessas requer representatividade para todos os níveis das variáveis qualitativas na amostra, o que nem sempre é possível (MARTINS et al., 2016).

A inclusão de variáveis qualitativas em modelos tradicionais pode resultar em estimativas mais precisas, com maior realismo biológico, tornando a equação aplicável em diferentes locais. Porém, a aplicação dessas variáveis nos modelos tradicionais é de grande dificuldade, pois essas apresentam comportamento não linear, além de que pode aumentar a complexidade do modelo (LOUREIRO et al., 2016).

De acordo com Martins et al. (2016), o uso de RNA é uma alternativa interessante para estimar a altura das árvores em povoamentos florestais. As RNA são assim denominadas porque o funcionamento se assemelha ao do cérebro humano em alguns aspectos, e podem ser definidas como modelos matemáticos constituídos de unidades de processamento simples denominadas neurônios AGRARIAN ACADEMY, Centro Científico Conhecer - Goiânia, v.6, n.11; p. 341 
artificiais, que estão dispostas em camadas. O uso de RNA tem se mostrado como uma alternativa promissora no manejo dos recursos florestais, em substituição às técnicas de regressão, gerando resultados eficientes.

Como é visto em Binoti et al. (2013) que estimaram a altura de povoamentos equiâneos de Eucalyptus sp., Castro et al. (2013) realizaram o estudo do crescimento e produção de plantios comerciais de eucalipto com uso de RNA, Binoti et al., (2014) utilizaram as redes para estimar o volume individual de Eucalyptus sp. Schikowski et al. (2015) descreveram a forma do fuste de Eucalyptus sp. utilizando redes neurais artificiais, e Castro et al. (2015) efetuaram a modelagem do crescimento e produção de Eucalyptus sp. com o uso de RNA. Os estudos com RNA, em geral, são relacionados com espécies introduzidas, de rápido crescimento, principalmente os gêneros Pinus e Eucalyptus. Estudos com espécies nativas geralmente não são realizados, por não despertarem interesse devido não existirem informações relativas à ecologia, silvicultura e biometria (TONINI et al., 2005).

Face ao exposto com objetivo de incrementar as informações existentes de modelagem biométrica com espécies nativas, o presente estudo buscou configurar, treinar e validar modelos de redes neurais artificiais para estimação de alturas de árvores individuais de um plantio da espécie Parapiptadenia rigida conhecida popularmente como angico-vermelho e comparar com os obtidos por meio da análise de regressão.

\section{MATERIAIS E MÉTODOS}

\section{Caracterização e localização da área de estudo}

O estudo foi realizado em um plantio de Parapiptadenia rigida (angicovermelho) com cinco anos e sete meses de idade, na área experimental da FEPAGRO Forrageiras, localizada no município de São Gabriel, região Sudoeste do Rio Grande do Sul, nas coordenadas 30²0'59'W, 54¹5'82'S, com altitude média de $137 \mathrm{~m}$. O local do estudo encontra-se sob o domínio do Bioma Pampa. O município apresenta clima do tipo $\mathrm{Cfa}$, de acordo com a classificação de Köppen, com uma precipitação total média anual de $1424,0 \mathrm{~mm}$ e temperatura média anual de $19,5 \stackrel{\circ}{\circ}$.

A área do plantio experimental apresenta vegetação campestre natural com grau médio de alteração, em função das atividades de pecuária extensiva de bovinos. As mudas de angico-vermelho foram produzidas em tubetes de $175 \mathrm{~cm}^{3} \mathrm{em}$ viveiro da FEPAGRO Florestas, e foram plantadas em outubro de 2012. O plantio foi realizado com espaçamento $2 \times 4 \mathrm{~m}$ com manutenção da pastagem nativa na entrelinha, em parcelas de $30 \times 36 \mathrm{~m}$. Outras práticas de manejo adotadas foram 0 cultivo mínimo, adubação na cova de plantio, replantio, controle da matocompetição e formigas.

O solo do local é classificado como argissolo vermelho distrófico latossólico, com a presença de horizonte $B$ textural de argila e baixa saturação por bases (EMBRAPA, 2006).

\section{Coleta dos dados}

Foi realizado um censo florestal na área do estudo, neste foram mensuradas todas as árvores maiores que 1,3 metros de altura, totalizando 196 árvores. As medidas de altura foram realizadas com clinômetro Haglöf e as medidas de diâmetro a altura do peito (DAP), tomadas a 1,3 metros, foram feitas com fita dendrométrica. 


\section{Análise dos dados}

No Quadro 1 são apresentados os cinco modelos hipsométricos utilizados para estimar a altura das árvores de Parapiptadenia rigida, para o ajuste dos modelos foram utilizados $70 \%$ dos pares de dados. Após o ajuste, foi realizada a validação, que consiste em aplicar os modelos ajustados nos $30 \%$ dos pares de dados não utilizados no ajuste, verificando assim a real eficiência dos modelos. Para realizar a análise de regressão foi utilizada a planilha eletrônica Excel (Microsoft® Office, 2016). Os modelos de regressão de natureza logarítmica [In (h)] necessitam que seja eliminada a discrepância logarítmica, para isso foi calculado o fator de correção de Meyer (Fc):

$$
F c=e^{0,5 * 5 \% x^{2}}
$$

QUADRO 1 - Modelos ajustados para estimar altura de Parapiptadenia rigida em área experimental situada no município de São Gabriel, Rio Grande do Sul.

\begin{tabular}{cc}
\hline Número & Modelos \\
\hline 1 & $\mathrm{~h}=\beta_{0}+\beta_{1} \cdot \mathrm{d}^{2}$ \\
2 & $\ln \mathrm{h}=\beta_{0}+\beta_{1} \cdot \ln \mathrm{d}$ \\
3 & $\ln \mathrm{h}=\beta_{0}+\beta_{1} \cdot \sqrt{\mathrm{d}}$ \\
4 & $\ln \mathrm{h}=\beta_{0}+\beta_{1} \cdot(1 / \mathrm{d})+\beta_{2} \cdot\left(1 / \mathrm{d}^{2}\right)$ \\
5 & $\mathrm{~h}=\beta_{0}+\beta_{1} \cdot \ln \mathrm{d}$
\end{tabular}

Em que: $h$ - altura, em $m$; $d$ - diâmetro à altura do peito, em cm; $\beta_{0}, \beta_{1}$ e $\beta_{2-}$ coeficientes do modelo e In - logaritmo neperiano.

Foram utilizadas RNA do tipo perceptron de múltiplas camadas, conhecidas como MLP (Multilayer Perceptron). Foram treinadas 100 RNA, com um, dois, três e quatro neurônios na camada oculta, com variável de entrada DAP (quantitativa) e a variável de saída altura (quantitativa) todos configuradas por meio do software NeuroForest 4.0. Para realizar o treino foram utilizados $70 \%$ dos pares de dados. Após o treinamento, foram selecionadas a RNA com $100 \%, 90 \%$ e $80 \%$ de eficiência de cada treinamento com diferentes neurônios, baseado nos resultados estatísticos de raiz quadrada do quadrado médio do erro e correlação. Com $30 \%$ dos pares de dados foi realizada a validação das redes e novamente verificada a eficiência a partir dos resultados estatísticos.

O tipo de treinamento utilizado foi o Resilient Propagation, com função de ativação sigmoidal na camada oculta e de saída. O algoritmo de treinamento Resilient Propagation, representa uma variante do algoritmo backpropagation (retropropagação do erro), e tem como vantagem a facilidade de calcular e adquirir aprendizagem sobre determinado problema, pelo fato de seu ajuste de pesos dependerem mais do sinal dos gradientes de erro, além de ser mais eficiente e recomendado para RNA do tipo Multilayer Perceptron (RIEDMILLER; BRAUN, 1993).

Para a parada do treinamento das redes foi utilizado o método descrito por Leal et al. (2015), em que o número total de ciclos seja igual a 3.000 ou o erro quadrático médio inferior a $1 \%$. Assim o treinamento é encerrado quando um dos critérios é atingido. 
A comparação das estimativas obtidas por regressão e RNA foi realizada através da avaliação de critérios estatísticos, sendo utilizado, o coeficiente de correlação (), raiz quadrada do quadrado médio do erro (RQME) e análise gráfica dos resíduos em percentagem (E\%), representados pelas seguintes fórmulas:

$$
\begin{aligned}
\mathrm{r}_{\mathrm{YY}} & =\frac{\operatorname{Cov}(\mathrm{Y}, \widehat{\mathrm{Y}})}{\sqrt{\mathrm{S}^{2}(\mathrm{Y}) \mathrm{S}^{2}(\widehat{\mathrm{Y}})}} \\
\mathrm{RQME} & =\sqrt{\mathrm{n}^{-1} \sum_{\mathrm{i}=1}^{\mathrm{n}}\left(\mathrm{Y}_{\mathrm{i}}-\widehat{\mathrm{Y}}\right)^{2}} \\
\mathrm{E} \% & =\frac{(\mathrm{Y}-\widehat{\mathrm{Y}})}{\mathrm{Y}}, 100
\end{aligned}
$$

Em que: $Y$ - altura observada; $\widehat{Y}$ - altura estimada; $S^{2}$ - variância; Cov. - covariância; n - número de observações.

A eficiência das estimativas de altura foi verificada seguindo o critério proposto por Thiersch (1997), são atribuídos pesos aos resultados estatísticos [ $\mathrm{r}_{\mathrm{Y} \hat{Y}}$, RQME e E\%], sendo a designação do melhor modelo feita pela somatória dos escores, valores de $1 \mathrm{a} n$, onde a menor soma dos escores indica a seleção da equação.

\section{RESULTADOS}

Para descrição da altura das árvores de Parapiptadenia rigida, foi realizado censo florestal de um plantio monoespecífico, resultando em 196 observações, cujos valores médio, mínimo, máximo, mediana e desvio padrão encontram-se na Tabela 1.

TABELA 1 - Valores mínimo, média, mediana, máximo e desvio padrão para plantio monoespecífico da espécie Parapiptadenia rigida no município de São Gabriel no estado do Rio Grande do Sul.

\begin{tabular}{cccccc}
\hline Variável & Mínimo & Média & Mediana & Máximo & Desvio Padrão \\
\hline DAP $(\mathrm{cm})$ & 0,795 & 4,079 & 3,809 & 10,663 & 2,164 \\
$\mathrm{~h}(\mathrm{~m})$ & 1,600 & 3,706 & 3,565 & 7,700 & 1,273 \\
\hline
\end{tabular}

Fonte: Autores (2019).

Os resultados do ajuste e de validação dos cinco modelos hipsométricos são apresentados na Tabela 2.

TABELA 2 - Critérios estatísticos dos modelos ajustados e validados com seus respectivos coeficientes para estimativa de altura da espécie Parapiptadenia rigida no município de São Gabriel no estado do Rio Grande do Sul.

\begin{tabular}{ccccccc}
\hline \multicolumn{7}{c}{ Ajuste } \\
\hline Modelo & $\boldsymbol{\beta}_{\mathbf{0}}$ & $\boldsymbol{\beta}_{\mathbf{1}}$ & $\boldsymbol{\beta}_{\mathbf{2}}$ & $\mathbf{F C}$ & $\mathbf{r}_{\mathbf{Y Y}}$ & $\mathbf{R Q M E}$ \\
\hline 1 & 2,7325 & 0,0453 & & & 0,7382 & 0,8543 \\
2 & 0,5931 & 0,5203 & & 1,3135 & 0,8117 & 0,7385 \\
AGRARIAN ACADEMY, Centro Científico & Conhecer - Goiânia, v.6, n.11; p. 344 & & 2019
\end{tabular}




\begin{tabular}{|c|c|c|c|c|c|c|}
\hline $\begin{array}{l}3 \\
4 \\
5 \\
\end{array}$ & $\begin{array}{r}0,1641 \\
1,9857 \\
1,4499 \\
\end{array}$ & $\begin{array}{c}0,5551 \\
-3,0011 \\
1,7899 \\
\end{array}$ & 1,7239 & $\begin{array}{l}1,3441 \\
1,3105\end{array}$ & $\begin{array}{l}0,7966 \\
0,8138 \\
0,8035 \\
\end{array}$ & $\begin{array}{l}0,7691 \\
0,7354 \\
0,7503 \\
\end{array}$ \\
\hline \multicolumn{7}{|c|}{ Validação } \\
\hline Modelo & $\beta_{0}$ & $\beta_{1}$ & $\beta_{2}$ & Fc & $\mathbf{r}_{Y Y}$ & RQME \\
\hline 1 & 2,7325 & 0,0453 & & & 0,6410 & 0,9815 \\
\hline 2 & 0,5931 & 0,5203 & & 1,3314 & 0,7963 & 0,7566 \\
\hline 3 & 0,1641 & 0,5551 & & 1,4263 & 0,7522 & 0,8427 \\
\hline 4 & 1,9857 & $-3,0011$ & 1,7239 & 1,3113 & 0,8067 & 0,7362 \\
\hline 5 & 1,4499 & 1,7899 & & & 0,8024 & 0,7387 \\
\hline
\end{tabular}

Em que: $\beta_{0}, \beta_{1}$ e $\beta_{2}$ - coeficientes de regressão estimados; Fc - fator de correção; $r_{\mathrm{Y}}$ - coeficiente de correlação; RQME - raiz quadrada do quadrado médio do erro.

Fonte: Autores (2019).

Com a divisão de parte dos dados para ajuste $(70 \%)$ e validação $(30 \%)$ foi possível observar que nem sempre os modelos são eficientes como parecem. No ajuste foram obtidos resultados satisfatórios. Tratando-se a Parapiptadenia rigida uma espécie de ocorrência natural, estudada de forma insipiente, com características genéticas peculiares e ainda pouco plantada na forma homogênea, percebe-se a diferença entre os melhores resultados obtidos para os ajustes de modelos hipsométricos apresentados por espécies exóticas como eucalipto, corriqueiramente estudas, e que demonstram características mais desejáveis para este tipo de estudo. Com os parâmetros obtidos no ajuste foram estimadas as alturas das árvores do conjunto de dados de validação, verificando que houve redução da correlação e aumento do erro das estimativas. $O$ modelo 1 foi o que apresentou os piores resultados no ajuste e com a validação a eficiência foi ainda mais reduzida, a $r_{Y \hat{Y}}$ passou de 0,7382 no ajuste para 0,6410 na validação e o RQME 0,8543 para 0,9815 .

O melhor modelo tanto no ajuste como na validação foi o modelo 4,que apresentou $r_{\mathrm{YY}}$ de 0,8138 no ajuste e 0,8067 na validação e RQME de 0,7354 no ajuste e 0,7362 na validação, é notável que neste modelo a eficiência não foi tão afetada e os critérios estatísticos analisados foram satisfatórios, podendo este ser utilizado para predição de altura das árvores de angico-vermelho da área do estudo.

Dentre as 100 RNA treinadas para cada quantidade de neurônios $(1,2,3$ ou 4) na camada oculta, foram selecionadas três redes baseadas na sua eficiência, sendo $100 \%, 90 \%$ e $80 \%$ de eficiência. Os resultados estatísticos obtidos para ajuste e validação das redes são apresentados na Tabela 3.

TABELA 3 - Critérios estatísticos das RNA treinadas e validadas para estimativa de altura da espécie Parapiptadenia rigida no município de São Gabriel no estado do Rio Grande do Sul.

\begin{tabular}{cccc}
\hline \multicolumn{3}{c}{ Ajuste } & \\
\hline RNA (Eficiência \%) & Neurônios na camada oculta & ryY & RQME \\
\hline $1(100 \%)$ & 1 & 0,8150 & 0,7295 \\
$2(90 \%)$ & 1 & 0,6210 & 0,9970 \\
$3(80 \%)$ & 1 & 0,4437 & 1,1431 \\
$4(100 \%)$ & 2 & 0,8206 & 0,7190 \\
$5(90 \%)$ & 2 & 0,8180 & 0,7240
\end{tabular}




\begin{tabular}{cccc}
$6(80 \%)$ & 2 & 0,8174 & 0,7252 \\
$7(100 \%)$ & 3 & 0,8231 & 0,7144 \\
$8(90 \%)$ & 3 & 0,8191 & 0,7220 \\
$9(80 \%)$ & 3 & 0,8181 & 0,7239 \\
$10(100 \%)$ & 4 & 0,8236 & 0,7134 \\
$11(90 \%)$ & 4 & 0,8219 & 0,7167 \\
$12(80 \%)$ & 4 & 0,8200 & 0,7202 \\
\hline RNA (Eficiência \%) & Validação & & \\
\hline $1(100 \%)$ & Neurônios na camada oculta & ryy & RQME \\
$2(90 \%)$ & 1 & 0,3958 & 1,1680 \\
$3(80 \%)$ & 1 & 0,4096 & 1,1588 \\
$4(100 \%)$ & 1 & 0,4213 & 1,1587 \\
$5(90 \%)$ & 2 & 0,7533 & 0,8192 \\
$6(80 \%)$ & 2 & 0,8234 & 0,6979 \\
$7(100 \%)$ & 2 & 0,3516 & 1,1943 \\
$8(90 \%)$ & 3 & 0,8319 & 0,6812 \\
$9(80 \%)$ & 3 & 0,8252 & 0,6941 \\
$10(100 \%)$ & 3 & 0,8304 & 0,6840 \\
$11(90 \%)$ & 4 & 0,6952 & 0,8247 \\
$12(80 \%)$ & 4 & 0,7034 & 0,8205 \\
\hline & 4 & 0,7014 & 0,8216 \\
\hline
\end{tabular}

Em que: $r_{\mathrm{YY}}$ - coeficiente de correlação; RQME - raiz quadrada do quadrado médio do erro. Fonte: Autores (2019).

Utilizando diferentes neurônios na camada oculta das RNA foi possível observar o quanto esse fator influência nas estimativas, podendo tanto subestimar como superestimar as alturas. No treinamento das redes foram obtidos resultados semelhantes no geral, com exceção das RNA com 1 neurônio na camada oculta com $90 \%$ de eficiência, no qual foram obtidos 0,6210 de $r_{\widehat{Y}}$ e 0,9970 de RQME, na rede com $80 \%$ de eficiência foi observado 0,4437 de $\mathrm{r}_{\mathrm{YY}}$ e 1,1431 de RQME.

Com a validação das redes foi verificada uma grande redução na eficiência, sendo de grande relevância principalmente as RNA apenas um neurônio na camada oculta e dois neurônios com $80 \%$ de eficiência, que tiveram resultados bem inferiores aos modelos hipsométricos testados e neste caso as alturas estimadas foram menores que as alturas observadas. A pior rede foi a com dois neurônios na camada oculta com $80 \%$ de eficiência, foi verificado 0,3516 de $r_{\mathrm{YY}}$ e 1,1943 de RQME.

As RNA com quatro neurônios na camada oculta na validação não tiveram resultados satisfatórios, devido superestimarem a altura das árvores, diferente do que é observado na validação, em que a rede com quatro neurônios na camada oculta e $100 \%$ de eficiência teve a melhor $r_{Y Y}$ e RQME, sendo 0,8236 e 0,7134, respectivamente. Na validação a rede com os melhores resultados foi a com três neurônios e $100 \%$ de eficiência, que obteve $r_{Y Y}$ de 0,8319 e RQME de 0,6812, sendo estes resultados os melhores comparados com os demais resultados de validação e ajuste e também com os modelos hipsométricos.

Com estes resultados é possível dizer que para um conjunto de dados menor, como é o caso do conjunto de validação, não é necessária uma grande quantidade 
de neurônios na camada oculta, e assim se fosse utilizada uma rede com mais neurônios seriam obtidas estimativas tendenciosas.

Redes Neurais Artificiais geralmente são utilizadas para estimar dados de bigdata, ou seja, conjunto de dados gigantescos, portanto quando se trabalha com conjuntos menores deve-se tomar cuidado na quantidade de neurônios definidos para a camada oculta, para assim obter estimativas realmente eficientes. Além disso, para se estimar altura de árvores é visto na literatura que não são necessárias arquiteturas complexas das redes, ou seja, com poucos neurônios já são obtidos resultados satisfatórios.

Portanto nas condições da área em estudo a melhor técnica para estimativa da altura das árvores é a RNA treinada com três neurônios na camada oculta com $100 \%$ de eficiência, que comparada a todas as outras redes e também aos modelos hipsométricos apresentou os melhores resultados, porém o melhor modelo ajustado também poderia ser utilizado.

Na Figura 1 é apresentado o gráfico de resíduos, composto pela frequência de resíduos em função das classes de resíduos para as melhores redes com 1, 2, 3 e 4 neurônios na camada oculta e o melhor modelo de regressão validado. 0 número após a sigla "RNA" representa a quantidade de neurônios utilizada na camada oculta.

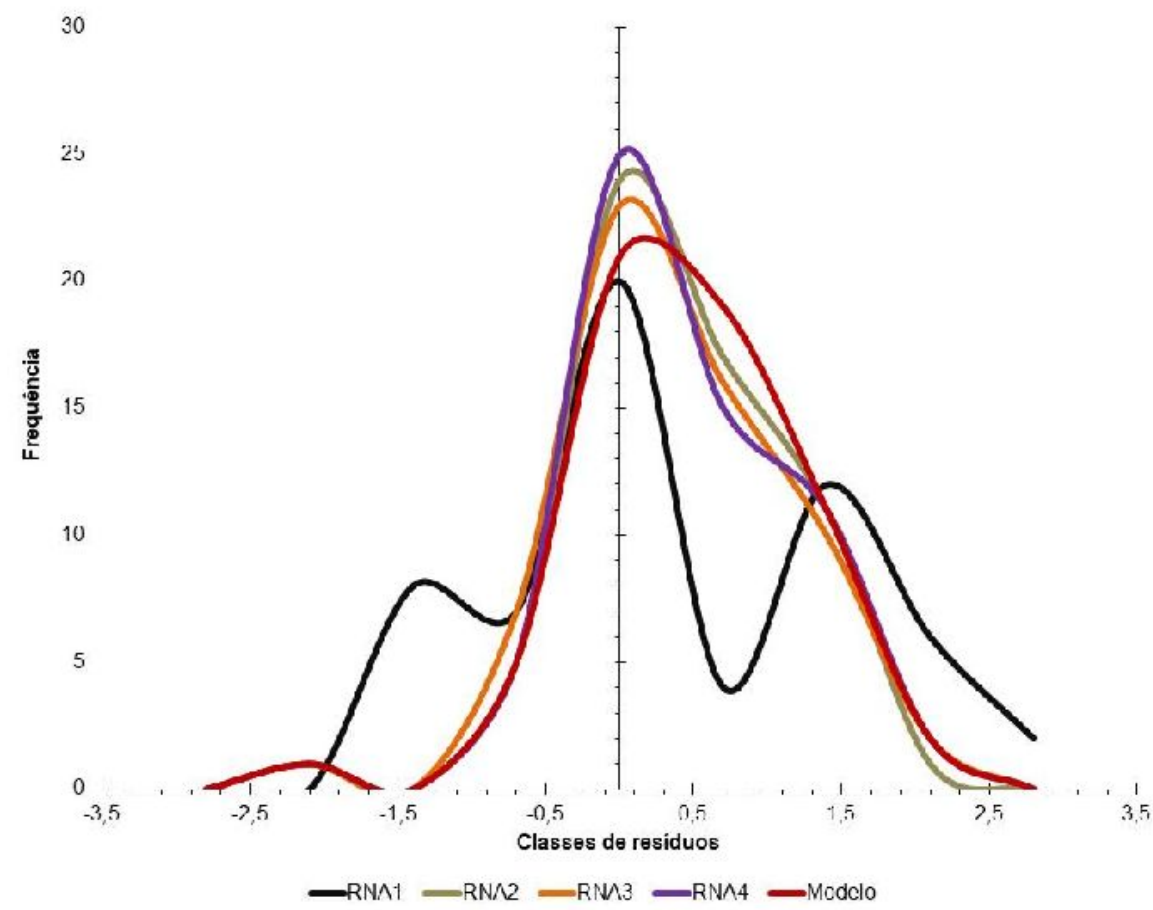

FIGURA 1 - Frequência de resíduos em função da classe de resíduos das melhores RNA com diferentes neurônios na camada oculta e melhor modelo de regressão validados para espécie Parapiptadenia rigida no município de São Gabriel no estado do Rio Grande do Sul. Fonte: Autores (2019).

É observado com esse gráfico menor quantidade de resíduos próximos a zero para a RNA com um neurônio na camada oculta com $80 \%$ de eficiência e para o modelo de regressão, além disso, estes apresentam amplitude maior de resíduos. Para a RNA1 a frequência foi 20 e a amplitude na classe de resíduos variou de -2,8 
a 2,8, o modelo obteve frequência 21 e a amplitude variou de $-2,1$ a 2,1. Apesar de serem resultados próximos e isso é visualmente notável, com os resultados estatísticos foi verificado que a RNA1 gerou os piores resultados. As RNA com 2, 3 e 4 neurônios na camada oculta ficam ainda mais parecidas visualmente. Foram obtidos 23, 24 e 25 de frequência para RNA3 com 100\% de eficiência, RNA2 com $90 \%$ de eficiência e RNA4 com 100\% de eficiência respectivamente, e amplitude da classe de resíduos variou de $-2,8$ a 2,8 para todas as RNA. Mesmo que a RNA2 e RNA4 tenham apresentado maior frequência de resíduos próximos a zero, a RNA3 obteve melhores resultados estatísticos, não subestimando e nem superestimando a altura das árvores.

$\mathrm{Na}$ Figura 2 são apresentadas as representações gráficas da altura observada versus altura estimada em função do diâmetro do melhor modelo de regressão (mod) e melhor Rede Neural Artificial (RNA), validados para o conjunto de dados da espécie Parapiptadenia rigida no município de São Gabriel no estado do Rio Grande do Sul.
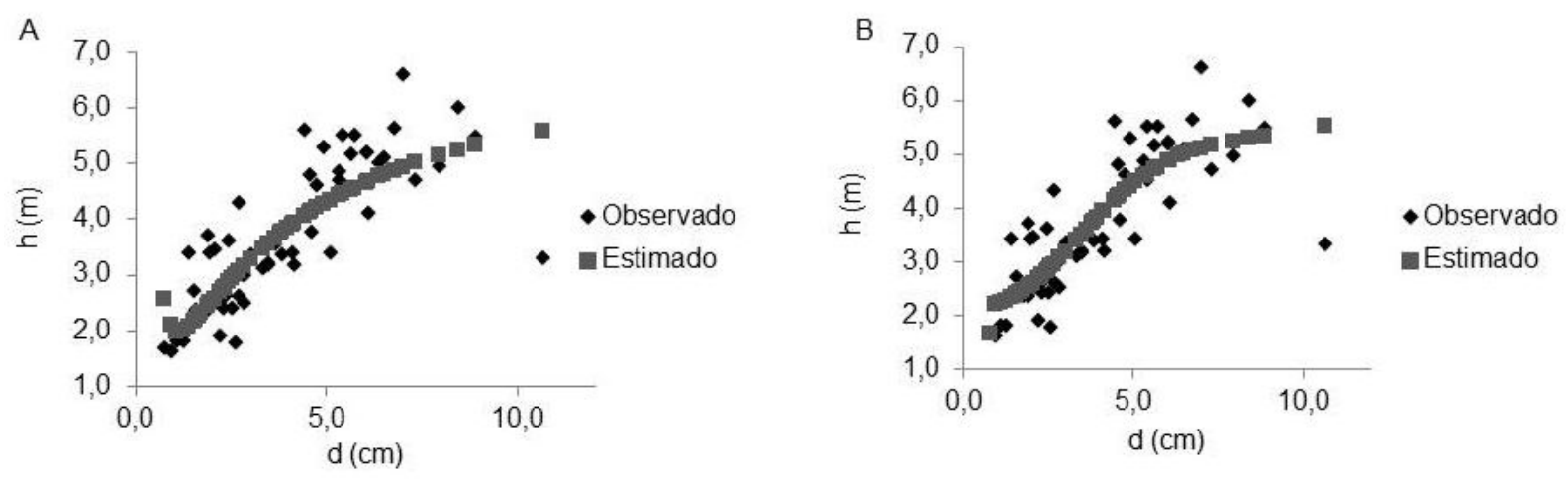

FIGURA 2 - Conjunto de dados observados versus estimados pelas melhores equações ajustadas (Mod), (A) e redes neurais artificiais (RNA), (B) para espécie Parapiptadenia rigida no município de São Gabriel no estado do Rio Grande do Sul. Fonte: Autores (2019).

Ambas as técnicas foram eficientes, cobrindo bem a nuvem de pontos observados, sendo que os resultados foram bem semelhantes visualmente. Tanto o modelo como a RNA para alturas maiores que quatro metros apresentaram discrepância dos resultados, assim como para uma árvore com cerca de três metros de altura na qual tanto os modelos hipsométricos como as RNA estimaram mais de cinco metros de altura. Por ser uma espécie nativa, resultados como esses são comuns de serem encontrados. Mesmo que os gráficos sejam parecidos, com os resultados estatísticos é possível notar que a RNA é mais eficiente, devido apresentar maior correlação entre as variáveis e menor erro das estimativas.

A Figura 3 apresenta o resultado do somatório dos escores dos modelos de regressão (mod) e Redes Neurais Artificiais (RNA) validadas para estimar altura das árvores de Parapiptadenia rigida no munícipio de São Gabriel no Estado do Rio Grande do Sul. No eixo horizontal, o número após a sigla "RNA" se refere a quantidade de neurônios na camada oculta, e o número entre parênteses se refere a eficiência da rede em estimar a altura. 


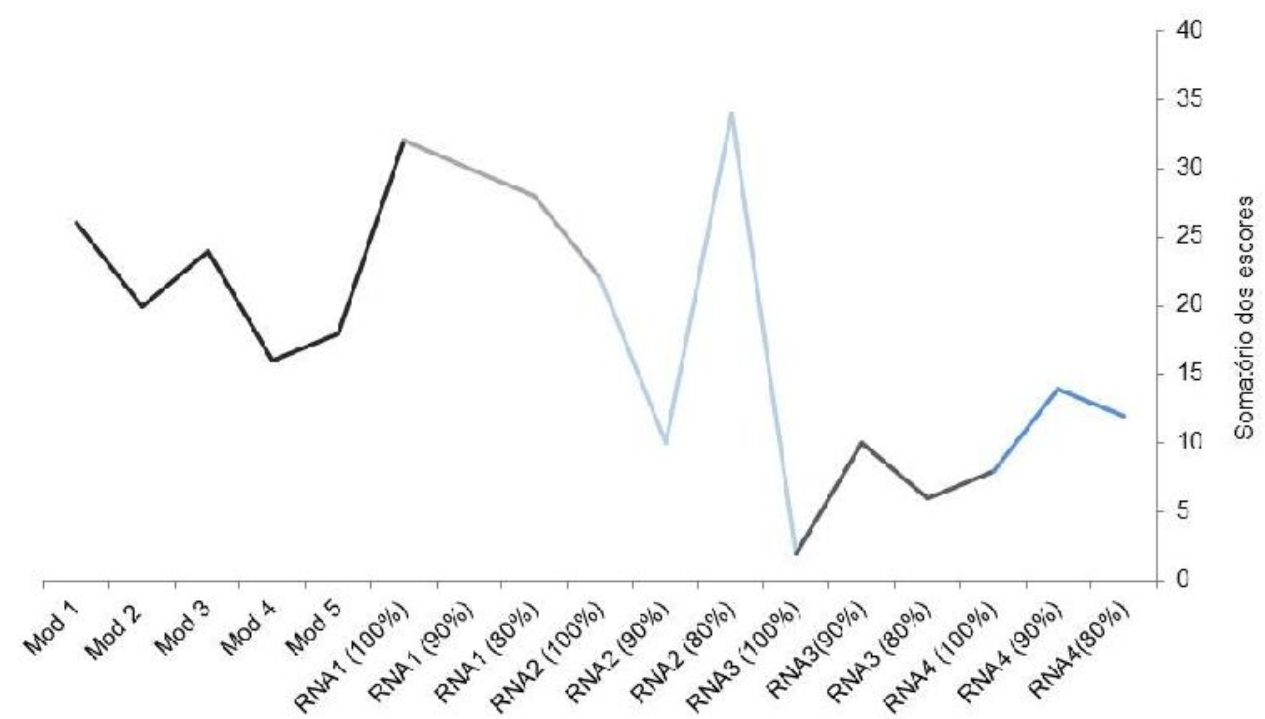

FIGURA 3 - Somatório de escores das melhores equações validadas (Mod) e redes neurais artificiais (RNA) validadas para estimativa de altura da espécie Parapiptadenia rigida no município de São Gabriel no estado do Rio Grande do Sul.

Fonte: Autores (2019).

É visto com este gráfico que nem sempre a RNA será eficiente, podendo estimar resultados piores do que um modelo de regressão. As redes validadas com um neurônio na camada oculta nos três níveis de eficiência obtiveram escore maior que os modelos de regressão. O pior resultado foi da RNA2 (80\%), que obteve 34 pontos. O melhor resultado foi obtido pela RNA3 (100\%), que acumulou apenas dois pontos. Para as redes validadas com quatro neurônios na camada oculta foram encontrados resultados melhores que dos modelos de regressão, porém essas RNA não foram tão eficientes devido superestimarem a altura das árvores.

\section{DISCUSSÃO}

Campos et al. (2016) estimaram a altura de plantios de pinus e eucalipto, formando um conjunto de 13.817 árvores em diferentes idades, ciclos e espaçamentos de plantio através de regressão convencional com diferentes modelos e redes neurais artificiais, com diferentes números de neurônios na camada oculta, variando de quatro a 16 neurônios. Conforme os resultados estatísticos dos modelos e das RNA, os autores selecionaram um modelo hipsométrico no qual foi obtido $r_{\mathrm{Y} \hat{Y}}=97,57 \%$ e RMSE $=5,30 \%$ e uma rede com $r_{\mathrm{YY}}=97,7 \%$ e RMSE $=$ $5,16 \%$, sendo que esta RNA foi treinada com apenas quatro neurônios na camada oculta.

Os autores concluíram que a estimativa da altura de árvores de diferentes espécies, em distintas condições de crescimento e locais, pode ser realizada utilizando uma única rede neural, com a mesma eficiência e exatidão obtida quando se utiliza as equações de regressão.

Binoti (2012) realizou um estudo com objetivo de estimar o volume de árvores, sendo testadas diversas configurações de RNA, foi verificado que configuração simples de RNA, com apenas um neurônio na camada oculta, apresentou resultados satisfatórios, provavelmente isto se justifica pelo número de neurônios na camada oculta ser responsável principalmente pela extração de características de não linearidades dos dados, e assim com um neurônio na camada AGRARIAN ACADEMY, Centro Científico Conhecer - Goiânia, v.6, n.11; p. 349 
oculta a RNA foi capaz de extrair a relação entre as variáveis consideradas e o volume. É recomendado o uso de configurações mais simples para a finalidade de estimar altura de árvores usando RNA, evitando ocorrência de overfitting, ou seja, a rede se ajusta muito bem a um conjunto de dados anteriormente observado, mas quando é aplicada em outro conjunto geralmente ocorrem superestimativas, resultando em valores tendenciosos (BRAGA et al., 2007).

Vendruscolo et al. (2017) em seu estudo tiveram como objetivo estimar a altura de árvores da espécie Tectona grandis com regressão convencional e com redes neurais artificiais, com isso, verificaram que ambas as técnicas são eficientes, porém as RNA proporcionam a obtenção de melhores estimativas que as obtidas por regressão, com erro inferior a 10\%. Vendruscolo et al. (2015) com o objetivo de estimar altura de eucaliptos por regressão e RNA afirmaram que tanto as estimativas por regressões como por redes são eficientes, no entanto, as redes são levemente superiores estatisticamente e tem a vantagem de usar variáveis categóricas.

Cordeiro et al. (2015) realizaram um estudo com objetivo de estimar o volume de árvores da espécie Acacia mangium, obtendo melhores resultados com a utilização das redes, que se mostraram mais acuradas que os modelos volumétricos convencionais.

\section{CONCLUSÕES}

As alturas estimadas por técnicas de redes neurais artificiais são mais acuradas quando comparadas aos modelos de regressão. Porém, ambas as técnicas podem ser utilizadas para estimar altura das árvores de Parapiptadenia rigida situadas no local em estudo.

Não há necessidade de utilizar uma RNA complexa para estimar a altura das árvores, ou seja, ao utilizar uma grande quantidade de neurônios na camada oculta pode gerar resultados superestimados.

Com a separação do conjunto de dados para ajuste e validação são obtidos resultados mais coerentes.

\section{REFERÊNCIAS}

BINOTI, M. L. M. S.; BINOTI, D. H. B.; LEITE, H. G.. Aplicação de redes neurais artificiais para estimação da altura de povoamentos equiâneos de eucalipto. Revista Árvore, v.37, n.4, p.639-645, 2013. Disponível em: http://www.scielo.br/pdf/rarv/v37n4/07.pdf. DOI: http://dx.doi.org/10.1590/S010067622013000400007.

BINOTI, M. L. M. S. Emprego de redes neurais artificiais em mensuração e manejo florestal. 2012. 138 f. Tese (Doutorado em Manejo Florestal; Meio Ambiente e Conservação da Natureza; Silvicultura; Tecnologia e Utilização de) Universidade Federal de Viçosa, Viçosa, 2012. Disponível em: http://www.locus.ufv.br/handle/123456789/579.

BINOTI, M. L. M.; BINOTI, D. H. B.; LEITE, H. G.; GARCIA, S. L. R.; FERREIRA, M. $Z$. et al. Redes neurais artificiais para estimação do volume de árvores. Revista Árvore, v.38, n.2, p.283-288, 2014. Disponível em: http://www.scielo.br/pdf/rarv/v38n2/08.pdf. DOI: http://dx.doi.org/10.1590/s010067622014000200008. 
BRAGA, A. P.; CARVALHO, A. C. P. L. F.; LUDERMIR, T. B.. Redes neurais artificiais: teoria e aplicação. Rio de Janeiro: LTC, 2007. 262 p.

CAMPOS, B. P. F.; SILVA, G. F.; BINOTI, D. H. B.; MENDONÇA, A. R.; LEITE, H. G. Predição da altura total de árvores em plantios de diferentes espécies por meio de redes neurais artificiais. Pesquisa Florestal Brasileira, v.36, n.88, p.375-385, 2016. Disponível em: https://pfb.cnpf.embrapa.br/pfb/index.php/pfb/article/view/1166/0. DOI: http://dx.doi.org/10.4336/2016.pfb.36.88.1166.

CASTRO, R. V. O.; SOARES, C.P. B.; MARTINS, F. B.; LEITE, H. G. Crescimento e produção de plantios comerciais de eucalipto estimados por duas categorias de modelos. Pesquisa Agropecuária Brasileira, v.48, n.3, p.287-295, 2013. Disponível em: $\quad$ https://seer.sct.embrapa.br/index.php/pab/article/view/12844. DOI: http://dx.doi.org/10.1590/s0100-204x2013000300007.

CASTRO, R. V. O.; CUNHA, A. B.; SILVA, L. V.; LEITE, H. G; SILVA, A. A. L. Modelagem do crescimento e produção para um povoamento de Eucalyptus utilizando dois métodos para quantificação do índice de local. Scientia Forestalis, v.43, n.105, p.83-90, 2015 Disponível em: https://www.ipef.br/publicacoes/scientia/nr105/cap08.pdf.

CORDEIRO, M. A.; PEREIRA, N. N. J.; BINOTI, D. H. B.; BINOTI, M. L. M. S.; LEITE, H. G. Estimativa do volume de Acacia mangium utilizando técnicas de redes neurais artificiais e máquinas vetor de suporte. Pesquisa Florestal Brasileira, v.35, n.83, p.255-261, 2015. Disponível em: https://pfb.cnpf.embrapa.br/pfb/index.php/pfb/article/view/596. DOI: https://doi.org/10.4336/2015.pfb.35.83.596.

Embrapa. Sistema Brasileiro de Classificação de Solo. 2. ed., Brasília: EMBRAPA, 2006. 306p.

LEAL, F. A.; MIGUEL, E. P.; MATRICARDI, E. A. T.; PEREIRA, R. S. Redes neurais artificiais na estimativa de volume em um plantio de eucalipto em função de fotografias hemisféricas e número de árvores. Revista Brasileira de Biometria, v.33, n.2, p.233-249, 2015.2 Disponível em: http://jaguar.fcav.unesp.br/RME/fasciculos/v33/v33_n2/A8_Fabricio_Eder_Eraldo.pdf

LOUREIRO, G. H.; SANQUETTA, C. R.; CASTRO, R. V. O.; ARCE, J. E. Estimativa da altura por meio de regressão e redes neurais artificiais para Pinus taeda L. Enciclopédia biosfera, Centro Científico Conhecer, v.13, n.24, p. 247-262, 2016. Disponível em: http://www.conhecer.org.br/enciclop/2016b/agrarias/estimativa\%20da\%20altura.pdf.

MARTINS, E. R.; BINOTI, M. L. M. da S.; LEITE, H. G.; BINOTI, D. H. B.; DUTRA, G. C. Configuração de redes neurais artificiais para estimação da altura total de árvores de eucalipto. Revista Brasileira de Ciências Agrárias, v.11, n.2, p.117123, 2016. Disponível em: http://www.agraria.pro.br/ojs2.4.6/index.php?journal=agraria\&page $=$ article $\&$ op $=$ view $\&$ path $\% 5 \mathrm{~B} \% 5 \mathrm{D}=$ agraria_v 11i2a5373. DOI: 10.5039/agraria.v11i2a5373. 
RIEDMILLER, M.; BRAUN, H. A direct adaptive method for faster back propagation learning: The RPROP algorithm. Neural Networks, 1993., IEEE International Conference on. IEEE, 1993, p. 586-591.

SCHIKOWSKI, A. B.; CORTE, A. P. D.; SANQUETTA, C. R. Estudo da forma do fuste utilizando redes neurais artificiais e funções de afilamento. Pesquisa Florestal Brasileira, v.35, n.82, p.119-127, 2015. Disponível em: https://pfb.cnpf.embrapa.br/pfb/index.php/pfb/article/view/867. DOI: http://dx.doi.org/10.4336/2015.pfb.35.82.867.

THIERSCH, A. A eficiência das distribuições diamétricas para prognose da produção de Eucalyptus camaldulensis. 1997. 155f. Dissertação (Mestrado em Engenharia Florestal) - Universidade Federal de Lavras, Lavras, 1997. Disponível em: http://repositorio.ufla.br/handle/1/11770.

TONINI, H.; ARCO-VERDE, M. F.; SÁ, S. P. P. Dendrometria de espécies nativas em plantios homogêneos no Estado de Roraima - Andiroba (Carapa guianensis Aubl), Castanha-do-Brasil (Bertholletia excelsa Bonpl.), Ipê-roxo (Tabebuia avellanedae Lorentz ex Griseb) e Jatobá (Hymenaea courbaril L.). Acta Amazônica, v.35, n.3, p.353-362, $2005 . \quad$ Disponível em: http://www.scielo.br/pdf/aa/v35n3/v35n3a07.pdf.

VENDRUSCOLO, D. G. S.; CHAVES, A. G. S.; MEDEIROS, R. A.; SILVA, R. S.; SOUZA, H. S. et al. Estimativa da altura de árvores de Tectona grandis L.f. utilizando regressão e redes neurais artificiais. Nativa, v.5, n.1, p.52-58, 2017. Disponível em: http://periodicoscientificos.ufmt.br/ojs/index.php/nativa/article/view/3738. DOI: http://dx.doi.org/10.5935/2318-7670.v05n01a09.

VENDRUSCOLO, D. G. S.; DRESCHER, R.; SOUZA, H. S.; MOURA, J. P. V. M.; MAMORÉ, F. M. D. et al. Estimativa da altura de eucalipto por meio de regressão não linear e redes neurais artificiais. Revista Brasileira Biometria, v.33, n.4, p.556569, $2015 . \quad$ Disponível em: http://jaguar.fcav.unesp.br/RME/fasciculos/v33/v33_n4/A9_DiogoRonaldo.pdf. 